\title{
IS CLASSICAL ACID-ALKALI-ACID TREATMENT RESPONSIBLE FOR CONTAMINATION? AN ALTERNATIVE PROPOSITION
}

\author{
Christine Hatté ${ }^{\bullet}$ Jean Morvan $^{2} \cdot$ Claude Noury $^{1} \bullet$ Martine Paterne $^{1}$ \\ ABSTRACT. It is well known that, during the widely used AAA pretreatment (de Vries and Barendsen 1954), alkali treat- \\ ment is responsible for the incorporation of modern carbon due to the precipitation of atmospheric $\mathrm{CO}_{2}$ as carbonate. Until \\ now, the last step of the experiment, consisting in acid treatment (most of the time with hydrochloric acid) was considered to \\ be sufficient to eliminate all of lab contamination. But wood, peat and sediment present a complex molecular structure. Dur- \\ ing radiocarbon chemical treatments, functional groups still present in the molecules are likely to form ionic bonds with \\ "modern" carbonates. These new chemical bonds resist a "classical" acid treatment and are responsible for rejuvenation. This \\ short paper presents preliminary results for two common ${ }^{14} \mathrm{C}$ cases: rejuvenation of a 0.4 pMC wood and of an Oxygen Iso- \\ tope Stage 3 (OIS3) paleosol. For both cases, contamination due to incorporation of modern carbon during chemical treatment \\ is evaluated and an alternative protocol is proposed.
}

\section{INTRODUCTION}

Several studies were performed to determine the efficiency of the widely used AAA pretreatment (de Vries and Barendsen 1954), to eliminate contaminations incorporated during burial time or to exhaust the most reliable component for dating ( $\alpha$-cellulose, lignin, humin, humic acid, etc.) (Van Klinken and Hedges 1998). The aim of this paper is not to discuss the reliability of such or such fraction but only the possibility of contamination by modern carbon incorporation during the AAA pretreatment.

During the alkali step of AAA pretreatment, atmospheric $\mathrm{CO}_{2}$ is dissolved into solution. Three ways are then possible for this "modern" carbon:

1. $\mathrm{C}$ stays as ionic form $\left(\mathrm{CO}_{3}{ }^{2-}\right)$ in the solution and disappears during the last acid step,

2. $\mathrm{CO}_{2}$ precipitates as carbonate in the beaker or on the sample, and is dissolved during the acid step

3. C is incorporated into the sample structure as carbonate strongly linked with some electropositive atoms present in the sample structure or directly incorporated as a functional group of the sample. In that case, the conventional hydrochloric acid treatment can not destroy the ionic linkages formed between modern Carbon and sample structure.

Such a type of contamination through modern carbon incorporation into the sample structure can occur only for samples presenting some characteristics: sulfur-rich samples or samples containing tertiary or quaternary Nitrogen or showing functional groups that can be rearranged during the two first steps, permitting modern Carbon introduction during the alkali step. Wood, peat, paleosol are the samples most likely to be contaminated during classical AAA treatment.

To avoid such type of contamination, different ways are possible:

1. Reducing the alkali step time, but this step is important to eliminate humic acids often present in paleosols or peats.

2. Performing the alkali step under neutral atmosphere $\left(\mathrm{N}_{2}, \mathrm{He}\right.$, or $\left.\mathrm{Ar}\right)$, but it is expensive and not convenient with handling difficulties.

${ }^{1}$ Laboratoire des Sciences du Climat et de l'Environnement, UMR1572 CEA/CNRS, F-91198 Gif-sur-Yvette cedex, France. E-mail: hatte@1sce.cnrs-gif.fr.

${ }^{2}$ École Nationale Supérieure de Chimie de Rennes, Avenue du Général Leclerc, F-35700 Rennes, France

(C) 2001 by the Arizona Board of Regents on behalf of the University of Arizona RADIOCARBON, Vol 43, Nr 2A, 2001, p 177-182

Proceedings of the 17 th International ${ }^{14} \mathrm{C}$ Conference, edited by I Carmi and E Boaretto 
3. Finding a third step able to destroy ionic linkages existing between modern carbon and sample structure, and then discarding the contamination involved by the alkali step.

The third proposition seems to be the most adequate for ${ }^{14} \mathrm{C}$ preparation. Before finding the most appropriate treatment, the first aim of the investigation is to define the type of probable contamination.

\section{A PRIORI}

The two examples presented here are common ${ }^{14} \mathrm{C}$ samples, which are conventionally treated following the classical AAA treatment: an old wood, presenting a structure still, which is complex, and an iron-rich paleosol.

The wood, as vegetal remain, presents a reticulate structure, containing a certain amount of Nitrogen, Sulfur and functional groups $(-\mathrm{C}=\mathrm{O},-\mathrm{C}-\mathrm{O}, \mathrm{C}-\mathrm{N},-\mathrm{OH},-\mathrm{O}$-alkyl). Thus, it is difficult to choose the best dating fraction (lignin, $\alpha$-cellulose, etc.) and the adequate protocol (Leavitt and Danzer 1993; Zaitseva 1995; Hoper et al. 1998). In spite of remaining purification problems, the AAA pretreatment stays one of the widely used. During the first acid step, a replacement of some $\mathrm{OH}^{-}$groups (linked to quaternary nitrogen or to functional groups, for example) by $\mathrm{Cl}^{-}$could occur. As shown by Enkvist et al. (1958), who obtained anions exchanger resins with ammonia treated lignin, an exchange of anions groups into the sample structure could occur during the alkali treatment. Sarukhanyan and Belopol'skii (1954) showed that the modern $\mathrm{CO}_{2}$ incorporation happens first as ammonium carbamate and is next hydrolyzed into carbonate. On the other hand, as used in ionic chromatography based on the difference between retention times, affinity of sulfate or carbonate for exchanger groups is higher than affinity of chloride. This means, that during the alkali step of the AAA treatment, $\mathrm{Cl}^{-}$could be replaced by modern carbonate, resulting from incorporation of atmospheric $\mathrm{CO}_{2}$. This results in a modern carbon incorporation into the sample structure, as already suspected by Head et al. (1996). Due to a weaker ionic affinity, the last step of the "classical" chemical treatment with $\mathrm{HCl}$ is not able to break interactions formed with $\mathrm{CO}_{3}{ }^{2-}$. Thus, modern Carbon introduced during chemical treatment remains trapped within the sample and is responsible for rejuvenation. The only way to eliminate this contamination is to introduce as a last step, a component presenting a stronger ionic affinity than this one of carbonate.

Paleosols are a complex matrix which may contain multiple sources of carbon, depending on the soil type and texture (clay content, $\mathrm{pH}, \mathrm{FeII}, \mathrm{FeTot}$, etc.), the nature of the covering sediment, the top vegetation, the climatic parameters (precipitation, temperature, etc.), so that the dating of paleosols sometimes shows humic fractions that are younger than the residual humin fraction and sometimes they are older (for paleosols in loess sequence, see Head et al. 1989; Zhou et al. 1994). Likewise, the age varies with the fraction size or density (Trumbore and Zheng 1996). Here, we will only discuss the contamination possibility by modern carbon, by the way of a AAA pretreatment, id est when the humin fraction is chosen as dating support.

The paleosol studied here is a OIS3-paleosol present in loess sequences and corresponding to wetter and warmer periods than those characteristic of typical loess deposits. It contains a high amount of iron, essentially under the $\mathrm{Fe}^{2+}$ form, situated between the clay layers. During alkali treatment, $\mathrm{CO}_{3}{ }^{2-}$ from atmospheric $\mathrm{CO}_{2}$ could react with $\mathrm{Fe}^{2+}$ to form ferrous carbonate. This carbonate is insoluble, thus the last step of the "classical" chemical treatment (with $\mathrm{HCl}$ ) is not strong enough to break the new $\mathrm{Fe}-\mathrm{CO}_{3}$ bond. Thus, modern Carbon introduced during chemical treatment remains trapped within the sample released during the combustion step (decomposition temperature of $\mathrm{FeCO}_{3}$ around $430-450{ }^{\circ} \mathrm{C}$; Pascal 1958) and is responsible for rejuvenation. The only way to elim- 
inate this ferrous carbonate from the clayey structure is to oxidize FeII into FeIII and therefore break the complex formed by iron and carbonate.

\section{TREATMENTS}

In order to exhaust the contamination involved by the classical protocol, the AAA treatment was performed in the worst conditions: i.e. a long time in alkali solution (around $3 \mathrm{hr}$ ) to allow a significant $\mathrm{CO}_{2}$ dissolution and low temperature to thwart the carbonate precipitation (occurring preferentially at high temperature). If there is an incorporation of modern carbon within this step, this incorporation will be maximum and rejuvenation will be substantial.

\section{Treatments of Wood}

The classical AAA treatment consists of:

$\mathrm{HCl} 1 \mathrm{M}$ until total decarbonatation $\mathrm{NH}_{4} \mathrm{OH} 2.10^{-4} \mathrm{M}$ at $25-30{ }^{\circ} \mathrm{C}$ for about $3 \mathrm{hr}$ $\mathrm{HCl} 1 \mathrm{M}$ for $1 \mathrm{hr}$

In an alternative protocol, $\mathrm{HCl}$ is replaced by $\mathrm{H}_{2} \mathrm{SO}_{4}$ providing higher ionic affinity to replace the modern carbon, incorporated as carbonate into the sample structure. Two tests with different concentration of sulfuric acid were performed:

$$
\begin{array}{ll}
\mathrm{HCl} & 1 \mathrm{M} \text { until total decarbonatation } \\
\mathrm{NH}_{4} \mathrm{OH} & 2.10^{-4} \mathrm{M} \text { at } 25-30{ }^{\circ} \mathrm{C} \text { for around } 3 \mathrm{hr} \\
\mathrm{H}_{2} \mathrm{SO}_{4} & \text { 1) } 0.4 \mathrm{M} \text { for } 1 \mathrm{hr} \\
& \text { 2) } 2 \mathrm{M} \text { for } 2 \mathrm{hr}
\end{array}
$$

\section{Treatments of Paleosol}

The classical AAA treatment is presented in Hatté et al. (2001) and consists of:

$$
\begin{array}{ll}
\mathrm{HCl} & 1 \mathrm{M} \text { until total decarbonatation } \\
\mathrm{Na}_{4} \mathrm{P}_{2} \mathrm{O}_{7} & 0.1 \mathrm{M} \text { at } 25-30{ }^{\circ} \mathrm{C} \text { for around } 3 \mathrm{hr} \\
\mathrm{HCl} & 1 \mathrm{M} \text { for } 1 \mathrm{hr}
\end{array}
$$

\begin{tabular}{|c|c|}
\hline $\mathrm{HCl}$ & \\
\hline $\mathrm{Na}_{4} \mathrm{P}_{2} \mathrm{O}_{7}$ & $0.1 \mathrm{M}$ at $25-30^{\circ} \mathrm{C}$ for $3 \mathrm{hr}$ \\
\hline $\mathrm{K}_{2} \mathrm{Cr}_{4} \mathrm{O}_{7}$ & $0.1 \mathrm{M} / \mathrm{H}_{2} \mathrm{SO}_{4} 2 \mathrm{M}$ at $25^{\circ} \mathrm{C}$ for \\
\hline & 1) $6 \mathrm{hr}$ \\
\hline & 2) $13 \mathrm{hr}$ \\
\hline & 3) $18 \mathrm{hr}$ \\
\hline
\end{tabular}

In an alternative protocol, the last acid step is replaced by an oxidation step, following the Bird et al. (1999) suggestion. This step would enable to oxidize $\mathrm{Fe}^{2+}$ into $\mathrm{Fe}^{3+}$ and, consequently, decompose the ferrous carbonate. It consists in: 


\section{RESULTS AND DISCUSSION}

The different treatments were performed on a $0.4 \mathrm{pMC}$ wood and on an OIS-3 paleosol with very low organic carbon content. The results obtained are listed in Tables 1 and 2 and presented in Figures 1 and 2 for wood and paleosol respectively. Unfortunately, only two tests on the paleosol are available due to the low amount of organic carbon $(\mathrm{ABO} \times 6 \mathrm{hr})$ and to the large uncertainty $(\mathrm{ABO} \times 18$ hr). The amount of wood was big enough to permit $\beta$-counting analysis.

Table 1 Results from ${ }^{14} \mathrm{C}$ dating obtained on wood, following the different treatments (see text): sample code, treatment, and activity $(1 \sigma)$. Analyses were performed by $\beta$-counting.

\begin{tabular}{lcc}
\hline Sample code & Treatment & Activity $( \pm 1 \sigma)$ \\
\hline Gif-11405 & Brut & $0.97 \pm 0.31$ \\
Gif-11408 & Conventional AAA & $1.99 \pm 0.39$ \\
Gif-11461 & $\mathrm{H}_{2} \mathrm{SO}_{4} 0.4 \mathrm{M} \mathrm{1} \mathrm{hr}$ & $1.78 \pm 0.32$ \\
Gif-11491 & $\mathrm{H}_{2} \mathrm{SO}_{4} 2 \mathrm{M} 2 \mathrm{hr}$ & $0.56 \pm 0.26$ \\
\hline
\end{tabular}

Table 2 Results from ${ }^{14} \mathrm{C}$ dating obtained on paleosol, following the different treatments (see text): sample code, treatment, and activity $(1 \sigma)$. Analyses were performed by AMS.

\begin{tabular}{lcc}
\hline Sample code & Treatment & Activity $( \pm 1 \sigma)$ \\
\hline GifA-99608 & Conventional AAA & $7.30 \pm 0.15$ \\
GifA-99611 & ABOx, 6h & \\
GifA-99612 & ABOx, 13h & $3.15 \pm 0.11$ \\
GifA-99613 & ABOx, 18h & $2.64 \pm 1.87$ \\
\hline
\end{tabular}

\section{Treatments of Wood}

As shown in Figure 1, the untreated sample presents a higher activity than expected, thus showing that a chemical treatment to eliminate contaminations is necessary. The alkali step allowing the elimination of humic acid is certainly the most probable contaminant. But, the samples treated with the conventional AAA treatment presents a rejuvenation with an activity of $2.0 \pm 0.4 \mathrm{pMC}$ (around $31,500 \mathrm{yr} \mathrm{BP}$ ) instead of the expected $0.4 \mathrm{pMC}$ (around 44,000 yr BP), corresponding to an incorporation of $1.4 \% \mathrm{wt}$ of modern carbon. The first test with sulfuric acid instead of hydrochloric acid presents equivalent results with $1.8 \pm 0.3 \mathrm{pMC}$, but the second one, which is stronger, shows a sharp improvement, with an activity of $0.6 \pm 0.3 \mathrm{pMC}$ in agreement with the expected age. In agreement with differential ionic affinity strengths, it seems that sulfuric acid used during the last acid step, has sufficient ionic affinity to replace $\mathrm{CO}_{3}{ }^{2-}$ by $\mathrm{SO}_{4}{ }^{2-}$. In this way, it reduces the lab contamination.

\section{Treatments of Paleosol}

The two results obtained for the $\mathrm{ABOx}$ treatment present equivalent values with an activity of 3 pMC (around 28,000 yr BP), lower than the one obtained by conventional AAA treatment (7 pMC, around 21,000 yr BP). Thus, ages obtained by $\mathrm{ABOx}$ treatments are more consistent with the stratigraphical position of the paleosol. In the case of contamination as ferrous carbonate, the rejuvena- 


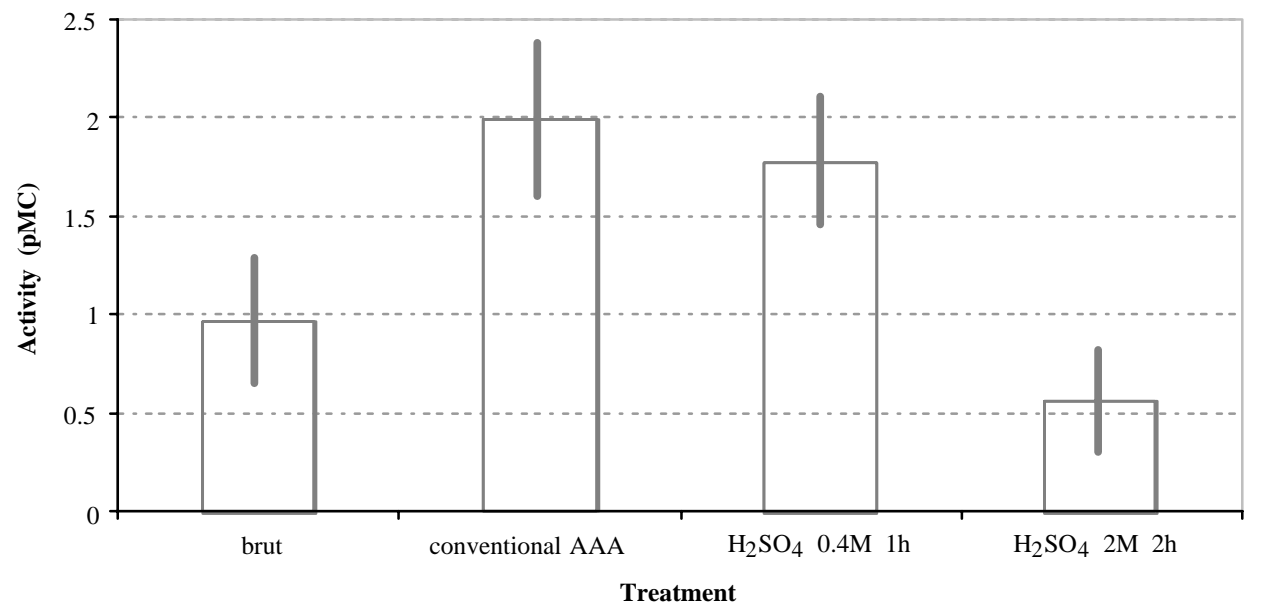

Figure 1 Treatments of wood. Activity and error margins obtained for a wood sample following different treatments (see text)

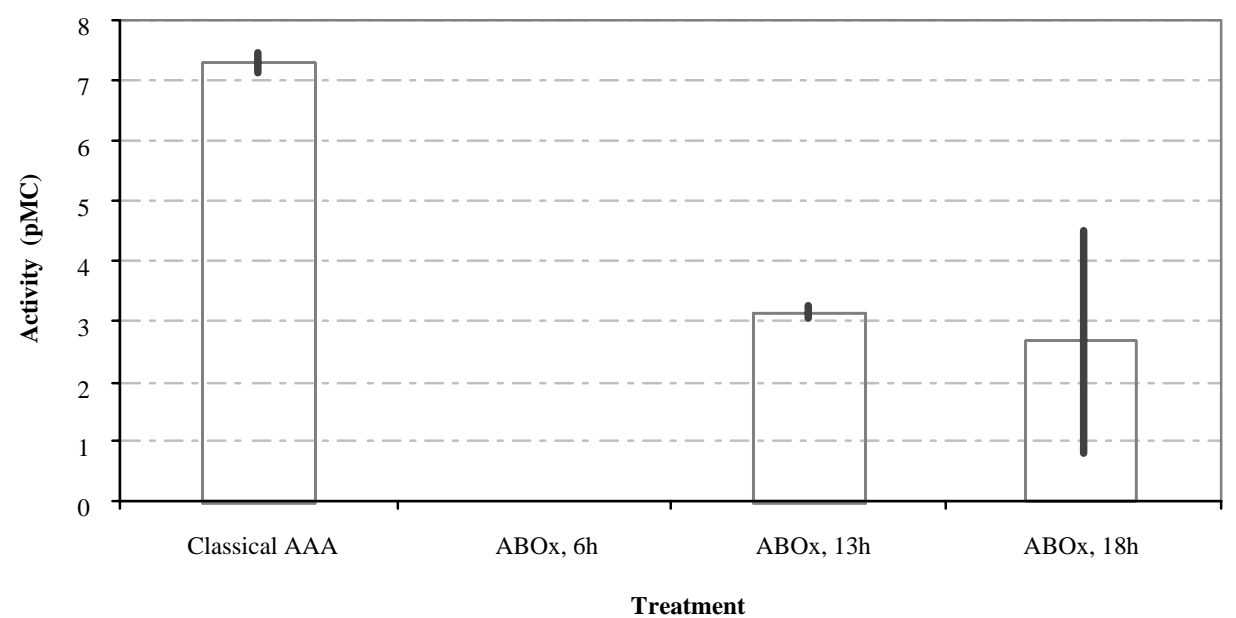

Figure 2 Treatments of paleosol. Activity and error margins obtained for a paleosol sample following different treatments (see text)

tion due to the conventional AAA treatment corresponds to an incorporation of around $3.9 \%$ of modern carbon, giving an age of around $21 \mathrm{ka}$ instead of the expected $28 \mathrm{ka}$. A step time of $13 \mathrm{hr}$ seems sufficient to oxidize FeII into FeIII and, consequently to eliminate modern carbon incorporated into the clay structure. But, due to the lack of result for the ABOx6h treatment, other attempts have to be performed to determine precisely the contact time in this step. Nevertheless, it seems that ABOx treatment allows the release of modern carbon, incorporated during the alkali step and complexed in the form of iron carbonates. So, ABOx treatment reduces the lab contamination.

In both cases, the lab contamination seems to be reduced thanks to the alternative protocol. Nevertheless, the lack of duplicates and the big error margins do not allow definitive conclusions. Further- 
more, several analysis (including organic mass spectrometry, NMR, IR, etc.) will have to be performed especially on wood sample to determine precisely where the modern carbon incorporation occurs. This is necessary to assess the contamination potentiality of samples.

\section{CONCLUSIONS}

We attempted two different chemical treatments as an alternative to the classical AAA treatment. It seems that a high ionic affinity acid treatment as last step allows to eliminate all modern carbon incorporated into wood structure during the alkali step, whereas an oxidizing treatment would be necessary to eliminate iron carbonates formed with modern carbon between clay layers of loess paleosols. Both alternatives proposed here as chemical treatment of wood and paleosols constitute promising improvements, nevertheless more attempts have to be performed to draw definitive conclusions.

\section{ACKNOWLEDGMENTS}

We would like to thank Dr Maurice Arnold for AMS ${ }^{14} \mathrm{C}$ analysis (UMS 2004). The CEA and the CNRS are acknowledged for financial support. Valuable comments from P Briend helped improving the English. This is LSCE (Laboratoire des Sciences du Climat et de l'Environnement) contribution $\mathrm{n}^{\circ} 2000-0501$

\section{REFERENCES}

Bird M, Ayliffe L, Fifield L, Turney C, Cresswell R, Barrows T, David B. 1999. Radiocarbon dating of "old" charcoal using a wet oxidation, stepped-combustion procedure. Radiocarbon 41(2):127-40.

Enkvist T, Kremer KE, Lehtonen P, Mölsä U. 1958. Attempts to prepare anion exchangers from lignin. Svensk Papperstidn 61:811-14.

Hatté C, Pessenda L CR, Lang A, Paterne M. 2001. Development of accurate and reliable ${ }^{14} \mathrm{C}$ chronologies for loess deposits. Application to the loess sequence of Nussloch (Rhine Valley, Germany). Radiocarbon. This issue.

Head MJ, Zhou W, Zhou M. 1989. Evaluation of ${ }^{14} \mathrm{C}$ ages of organic fractions of paleosols from loess-paleosol sequences near Xian, China. Radiocarbon 31(3): 68096.

Head MJ, Jacobsen G, Tuniz C. 1996. Assessement of the AAA pretreatment technique for charcoal and other organic materials used for ${ }^{14} \mathrm{C}$ AMS studies. Radiocarbon 38(1):46.

Hoper ST, McCormac FG, Hogg AG, Higham TFG, Head MJ. 1998. Evaluation of wood pretreatment on
Oak and Cedar. Radiocarbon 40(1):45-50

Leavitt SW, Danzer SR. 1993. Method for batch processing small wood samples to holocellulose for stable carbon isotope analysis. Analytical Chemistry 65:87-9.

Pascal P. 1958. Noveau traité de chimie minérale. Masson Edition XVIII. p 162-3.

Saukhanyan TA, Belopol'skii AP. 1954. Kinetics of absorption of carbon dioxide in aqueous ammonia. Zhur. Priklad. Khim. 27:712-21.

Trumbore S. and Zheng S. 1996. Comparison of fractionation methods for soil organic matter ${ }^{14} \mathrm{C}$ analysis. $\mathrm{Ra}$ diocarbon 38(2): 219-29.

Van Klinken J, Hedges JI. 1998. Chemistry strategies for organic ${ }^{14} \mathrm{C}$ samples. Radiocarbon 40(1):51-6.

de Vries H, Barendsen GW. 1954. Measurements of age by the carbon-14 technique. Nature 174:1138-41.

Zaitseva GI. 1995. Chemical composition and sample preparation of archaeological wood for radiocarbon dating. Radiocarbon 37(2):311-17.

Zhou W, An Z, Head MJ. 1994. Stratigraphic division of Holocene loess in China. Radiocarbon 36(1):37-45. 